\title{
PENGARUH PRODUCT QUALITY, BRAND EQUITY DAN IKLAN TERHADAP KEPUTUSAN PEMBELIAN PADA PRODUK OBAT NYAMUK VAPE
}

\section{Rasyid Ahmad Yoher ${ }^{1}$ I Wayan Santika ${ }^{2}$}

${ }^{1,2}$ Fakultas Ekonomi dan Bisnis Universitas Udayana, Bali, Indonesia e-mail: rasyid_achmed26@yahoo.co.id

\begin{abstract}
ABSTRAK
Persaingan bisnis dalam era globalisasi saat ini semakin dinamis, kompleks dan tidak pasti sehingga memacu para pengelola perusahaan untuk dapat berpikir secara kreatif dan inovatif agar selalu memberikan diferensiasi, serta keunggulan bagi perusahaannya dibandingkan dengan para pesaingnya. Tujuan penelitian adalah untuk mengetahui pengaruh product quality, brand equity, dan iklan terhadap keputusan pembelian konsumen pada produk obat nyamuk merek VAPE. Penelitian ini dilakukan di Kota Denpasar. Ukuran sampel yang digunakan sebanyak 120 responden. Dengan menggunakan teknik nonprobability sampling, khususnya purposive sampling. Data yang telah dikumpulkan diolah dengan menggunakan teknik analisis regresi linear berganda. Hasil penelitian menunjukkan setiap variabel yang diuji telah valid dan reliabel, serta telah layak secara model menurut uji asumsi klasik sehingga penelitian dapat dilakukan. Ketiga variabel bebas (product quality, brand equity dan iklan) berpengaruh positif dan signifikan terhadap keputusan pembelian konsumen pada produk obat nyamuk merek VAPE di Kota Denpasar.
\end{abstract}

Kata kunci: kualitas produk, ekuitas merek, iklan, keputusan pembelian

\section{ABSTRACT}

Business competition in the current era of globalization increasingly dynamic, complex and uncertain so as to spur the managers of the company to be able to think creatively and innovatively in order to always provide differentiation, as well as advantages for the company compared with its competitors. The purpose of this research is to know the effect of product quality, brand equity, and advertisement to consumer purchase decision on VAPE brand mosquito repellent product. This research was conducted in Denpasar City. The sample size used was 120 respondents. By using the technique of non-probability sampling, especially purposive sampling. The data that have been collected is processed by using multiple linear regression analysis technique. The results showed that each variable tested has been valid and reliable, and has been modeled according to the classical assumption test so that the research can be done. The three independent variables (product quality, brand equity and advertising) have a positive and significant effect on consumer purchasing decisions on VAPE brand mosquito repellent products in Denpasar City.

Keywords: product quality, brand equity, advertising, purchasing decisions 


\section{PENDAHULUAN}

Persaingan bisnis dalam era globalisasi saat ini semakin dinamis, kompleks dan tidak pasti sehingga memacu para pengelola perusahaan untuk dapat berpikir secara kreatif dan inovatif agar selalu memberikan diferensiasi, serta keunggulan bagi perusahaannya dibandingkan dengan para pesaingnya. Perusahaan dituntut untuk mengembangkan produknya dengan baik, menawarkan dengan harga yang menarik, dan membuatnya mudah diperoleh oleh pelanggan yang membutuhkan. Keputusan pembelian yang dilakukan pelanggan melibatkan keyakinan pelanggan pada suatu produk sehingga timbul rasa percaya diri atas kebenaran tindakan yang diambil. Rasa percaya diri pelanggan atas keputusan pembelian yang diambilnya mempresentasikan sejauh mana pelanggan memiliki keyakinan diri atas keputusannya memilih suatu produk.

Proses pengambilan keputusan pembelian pada setiap orang pada dasarnya adalah sama, namun proses pengambilan keputusan tersebut akan diwarnai oleh ciri kepribadian, usia, pendapatan dan gaya hidupnya. Menurut Schiffman dan Kanuk (2008) secara umum keputusan pembelian adalah seleksi dari dua atau lebih pilihan alternatif. Product quality (kualitas produk) saat ini sangat diperhatikan oleh konsumen. Konsumen menginginkan kualitas produk yang terbaik dalam melakukan keputusan pembelian. Menurut Kotler (2007) arti dari product quality adalah ciri dan karakteristik suatu barang atau jasa yang berpengaruh pada kemampuannya untuk memuaskan kebutuhan yang dinyatakan atau tersirat. Konsumen juga berorientasi pada prinsip dalam mengambil keputusan membeli berdasarkan keyakinannya (Ayu dan Kerti, 2014). Hal ini 
Rasyid Ahmad Yoher, Pengaruh Product Quality, Brand...

diperkuat oleh Ries (2000:51) yang mengatakan bahwa kualitas produk akan menjadi pertimbangan penting bagi pembelian. Menurut Shaharudin et al. (2010) Kualitas produk adalah faktor yang paling penting bagi pemilihan masing-masing merek atau model terutama di lingkungan pasar dimana tingkat persaingan adalah intens dan harga-kompetitif. Keputusan untuk membeli bukan hanya karena ikutikutan atau sekedar untuk mengejar gengsi, dapat dikatakan tipe ini lebih rasional. Sedangkan yang bertumpu pada emosional, keputusannya dalam membeli didominasi oleh konsumen lain. Produk-produk branded (bermerek) cenderung menjadi pilihannya dan tidak berpikir lebih lanjut akan manfaatnya Kambiz and Mohammad (2012).

Jalilvand et al. (2011) meneliti pengaruh product quality pada keputusan Commented [M1]: Ex. Jalilvand et al. (2011) pembelian, menemukan bahwa product quality memiliki pengaruh positif dan signifikan terhadap keputusan pembelian konsumen. Tariq dkk (2013) dan Tih \& Lee (2013) juga menemukan bahwa product quality berpengaruh positif dan signifikan terhadap keputusan pembelian konsumen. Hasil penelitian Rawung dkk (2015) menjelaskan bahwa product quality berpengaruh negatif dan tidak signifikan terhadap keputusan pembelian konsumen sepeda motor Suzuki PT. Sinar Galesong Pratama Manado karena merek Suzuki yang sudah banyak dikenal orang, serta PT. Sinar Galesong Pratama Manado memberikan harga yang dapat dijangkau oleh semua kalangan masyarakat sehingga konsumen tidak melihat kualitas produk lagi, itu disebabkan persaingan sekarang ini yang semakin ketat dengan banyaknya model sepeda motor yang dibuat oleh pesaing lainnya, 
sehingga konsumen hanya berpatokan pada merek dan harga yang ditawarkan perusahaan yang sesuai dengan kemampuan daya beli para pelanggan.

Mekanisme pasar yang memposisikan pemasar untuk selalu mengembangkan dan merebut pangsa pasar (market share) salah satu aset untuk mencapai keadaan tersebut adalah merek (brand) (Rofiq dan Nanang, 2009). Kecenderungan perkembangan persaingan pemasaran di masa mendatang akan menjadi persaingan antar merek, yaitu suatu persaingan untuk memperoleh dominasi merek. Merek akan menjadi asset perusahaan yang paling bernilai, karena merek lebih dari sekedar sebuah nama atau sebuah logo seperti sebuah hubungan lebih dari sekedar interaksi. Untuk itu merek perlu dikelola, dikembangkan, diperkuat dan ditingkatkan kualitasnya sehingga dapat memberikan keuntungan kompetitif. Pemilihan suatu merek, konsumen akan memilih suatu merek tertentu yang mencerminkan atau memperkuat identitas diri merek agar diterima dikomunitas tertentu. Kuenzel dan Halliday (2008:293) menyatakan bahwa orang biasanya melampaui identitas diri mereka untuk mengembangkan identitas sosial. Merek yang bertahan memiliki kekuatan untuk dapat mempengaruhi konsumen dalam mengkonsumsi atau menggunakan suatu produk tersebut. Jadi, ekuitas merek harus selalu dijaga keberadaannya agar produk tetap dibenak pelanggan yang tersalurkan dengan adanya keputusan pembelian (Nigam \& Kausik, 2011).

Kevin (2014) menyebutkan bahwa ketakutan merek terletak pada kemampuannya memikat konsumen untuk membeli produk yang diinginkannya. Merek penting bagi perusahaan untuk menunjukkan nilai produk yang ditawarkan 
Rasyid Ahmad Yoher, Pengaruh Product Quality, Brand...

ke pasar, namun merek tidak berarti jika tidak memiliki ekuitas yang kuat bagi pasar (Johan, 2010). Menurut Kotler dan keller (2009:263), brand equity adalah nilai tambah yang diberikan pada jasa produk dan jasa. Brand equity dapat tercermin dalam cara konsumen berpikir, merasa, dan bertindak dalam hubungannya dengan merek, harga, pangsa pasar, dan profitabilitas yang memberikan merek bagi perusahaan. Bagi perusahaan yang sadar akan makna penting dan startegis merek, brand equity menjadi hal yang selalu diperhatikan dan pengukurannya dilakukan secara teratur, karena brand equity dapat dianggap sebagai tambahan arus kas yang diperoleh melalui pengaitan nama merek dengan produk atau jasa yang mendasarinya (Eko dan Budi, 2013). Brand equity yang kuat dapat menyebabkan minat beli konsumen atau calon konsumen yang tinggi (Andrie dan Harold, 2013).

Pengetahuan tentang elemen-elemen ekuitas merek dan pengukurannya sangat diperlukan untuk menyusun langkah strategis dalam meningkatkan eksistensi merek yang akhirnya dapat meningkatkan jumlah pembelian konsumen (Orth et al. 2005). Ekuitas yang tinggi menjadi idaman setiap merek karena berarti bahwa merek-merek tersebut memiliki kedekatan dengan pasar dan pelanggan. Semakin kuat ekuitas merek suatu produk, maka akan semakin kuat pula daya tariknya bagi konsumen untuk membeli produk tersebut dan pada akhirnya akan memberikan keuntungan yang terus meningkat kepada perusahaan (Lee \& Leh, 2011). Gunawardane (2015) dalam penelitian mengemukakan bahwa brand equity berpengaruh positif dan signifikan terhadap keputusan pembelian konsumen. Hasil penelitian Ravie Rahmadhano (2014) menyatakan bahwa besarnya pengaruh 
dimensi brand equity secara parsial terhadap keputusan pembelian konsumen pada Peter Say Denim di Kota Bandung. Brand awarenes, perceived quality, brand association dan brand loyalty secara parsial berpengaruh positif dan tidak signifikan terhadap keputusan pembelian konsumen pada Peter Say Denim di Kota Bandung.

Iklan adalah segala bentuk penyajian dan promosi ide, barang atau jasa secara nonpersonal oleh suatu sponsor tertentu yang memerlukan pembayaran (Kotler \& Amstrong, 2001). Sedangkan Shimp (2003) mendefinisikan iklan sebagai suatu proses persuasi yang tidak langsung, yang didasari pada informasi tentang kelebihan suatu produk yang disusun sedemikian rupa sehingga menimbulkan rasa menyenangkan yang akan merubah pikiran orang untuk melakukan tindakan atau pembelian. Iklan (advertising) menurut (Peter \& Olson, 2000) adalah penyajian informasi nonpersonal tentang suatu produk, merek, perusahaan, atau toko yang dilakukan dengan bayaran tertentu. Iklan biasanya ditampakkan organisasi yang mensponsorinya. Informasi media periklanan yang lancar dan mudah dipahami oleh masyarakat (konsumen) akan memberikan tanggapan yang positif bagi konsumen. Menurut (Tjiptono, 2008) iklan dapat dimanfaatkan secara efektif untuk membangun citra jangka panjang produk maupun perusahaan dan juga dapat memicu pembelian segera. Penelitian yang dilakukan oleh Handayani dkk. (2012) menyatakan bahwa iklan mempunyai pengaruh positif dan signifikan terhadap keputusan pembelian konsumen. Penelitian Steven Edbert dkk. (2014) menjelaskan bahwa iklan berpengaruh positif dan tidak signifikan terhadap keputusan pembelian produk pasta gigi 
Rasyid Ahmad Yoher, Pengaruh Product Quality, Brand...

Pepsodent di kota Manado. Hal ini disebabkan karena konsumen sejak lama sudah percaya dan membeli produk Pepsodent tanpa memperhatikan informasi pada iklan yang dipublikasikan. Hasil penelitian yang berbeda dilakukan oleh Adyatma (2012) yang menyatakan bahwa iklan berpengaruh negatif dan signifikan terhadap keputusan pembelian konsumen. Hal ini disebabkan karena adanya perbedaan prilaku konsumen di Kota Manado dan di Kota Makassar.

VAPE merupakan salah satu produk obat nyamuk, selain BAYGON, HIT dan produk lainnya. Sejauh ini produk obat nyamuk merek VAPE dikalangan masyarakat merasa kurang dikenali dan kurang diminati dibandingkan merekmerek pesaing yang sudah terlebih dahulu ada maupun yang baru bermunculan. Sebenarnya ada beberapa keunggulan yang dimiliki oleh produk obat nyamuk VAPE dibandingkan produk obat nyamuk merek lainnya yaitu parfumnya yang lembut sehingga tidak menimbulkan sesak napas dan juga mengandung bahan aktif yang efektif untuk mengendalikan nyamuk dan relatif aman untuk kesehatan, obat nyamuk merek ini memiliki berbagai macam jenis, ada obat anti nyamuk bakar, pompa, mat, liquid, dan spray. Serta memiliki berbagai macam varian aroma yaitu lavender, orange, green tea, dan lemon.

VAPE juga ingin memenangkan persaingan dengan mampu terus melakukan beberapa terobosan inovasi terhadap produknya untuk mampu mengalahkan para pesaing, salah satunya dengan cara meningkatkan brand equity dibenak konsumen serta juga mampu dalam meningkatkan itensitas munculnya iklan produk obat nyamuk merek VAPE ini, baik di media cetak maupun elektronik. Kedepannya konsumen yang menjadi faktor utama dalam menentukan 
kesuksesan suatu produk dan akan tahu apa saja yang diinginkan konsumen dari sebuah obat anti nyamuk merek VAPE. Obat nyamuk VAPE menjadi objek penelitian karena obat nyamuk merek ini tergolong baru dan kurang dikenal dikalangan masyarakat, serta kedepannya ingin mengetahui seberapa banyak yang masyarakat yang sudah membeli dan menggunakan produk obat nyamuk merek tersebut, maka secara tidak langsung mampu mengetahui pengaruh product quality, brand equity dan iklan terhadap keputusan pembelian konsumen pada produk obat nyamuk merek VAPE tersebut.

Berdasarkan latar belakang masalah yang telah dipaparkan, rumusan masalah dalam penelitian ini adalah Apakah product quality berpengaruh signifikan terhadap keputusan pembelian konsumen pada produk obat nyamuk merek VAPE di Kota Denpasar, Apakah brand equity berpengaruh signifikan terhadap keputusan pembelian konsumen pada produk obat nyamuk merek VAPE di Kota Denpasar, Apakah iklan berpengaruh signifikan terhadap keputusan pembelian konsumen pada produk obat nyamuk merek VAPE di Kota Denpasar.

Berdasarkan rumusan masalah, maka tujuan dalam penelitian ini adalah Untuk mengetahui signifikansi pengaruh product quality terhadap keputusan pembelian konsumen pada produk obat nyamuk merek VAPE di Kota Denpasar., Untuk mengetahui signifikansi pengaruh brand equity terhadap keputusan pembelian konsumen pada produk obat nyamuk merek VAPE di Kota Denpasar, Untuk mengetahui signifikansi pengaruh iklan terhadap keputusan pembelian konsumen pada produk obat nyamuk merek VAPE di Kota Denpasar. 
Rasyid Ahmad Yoher, Pengaruh Product Quality, Brand...

Ackaradejruangsri (2013) menyatakan bahwa keputusan pembelian konsumen dipengaruhi oleh dimensi dari product quality dimana mempunyai pengaruh positif dan signifikan terhadap keputusan pembelian. Chi et al. (2008) menyatakan bahwa jika produk memiliki kualitas yang lebih baik, pelanggan akan lebih cenderung untuk membelinya. Jalilvand et al. (2011) menyatakan bahwa kualitas produk memiliki pengaruh positif dan signifikan terhadap keputusan pembelian konsumen. Gogoi et al. (2013); Dursun et al. (2011); Bao et al. (2011); Guterman (2012); Dick et al. (1995) menyatakan pula bahwa product quality berpengaruh positif dan signifikan terhadap keputusan pembelian konsumen. Berdasarkan teori dan penelitian sebelumnya maka dapat dirumuskan hipotesis penelitian sebagai berikut.

$\mathrm{H}_{1}$ : Product quality berpengaruh positif dan signifikan terhadap keputusan pembelian.

Monavvarian, (2015) menyatakan bahwa brand equity berpengaruh positif dan signifikan terhadap keputusan pemebelian konsumen. Lekprayura (2012) menyatakan brand equity berpengaruh positif dan signifikan terhadap keputusan pembelian. Gunawardane (2015) dalam penelitian mengemukakan bahwa brand equity berpengaruh dan signifikan terhadap keputusan pembelian. Heidarian (2015) dalam penelitian juga mengungkapkan bahwa brand equity berpengaruh positif dan signifikan terhadap keputusan pembelian konsumen. Berdasarkan teori dan penelitian sebelumnya maka dapat di rumuskan hipotesis penelitian sebagai berikut.

$\mathrm{H}_{2}$ : Brand equity berpengaruh positif dan signifikan terhadap keputusan pembelian. 
Remalya (2013) menyatakan bahwa periklanan berpengaruh positif dan signifikan terhadap keputusan pembelian konsumen. Penelitian yang dilakukan oleh Handayani dkk. (2012) mengenai pengaruh dari iklan terhadap keputusan pembelian konsumen juga mendapatkan hasil yang sama dimana iklan mempunyai pengaruh positif dan signifikan terhadap keputusan pembelian konsumen. Serta menurut penelitian yang dilakukan oleh Putri dan Putong (2012) periklanan berpengaruh positif dan signifikan terhadap keputusan pembelian konsumen. Berdasarkan teori dan penelitian sebelumnya maka dapat disimpulkan hipotesis sebagai berikut.

$\mathrm{H}_{3}$ : Iklan berpengaruh positif dan signifikan terhadap keputusan pembelian.

\section{METODE PENELITIAN}

Jenis penelitian ini menggunakan desain asosiatif, dimana desain asosiatif

Commented [M2]: First line $1 \mathrm{~cm}$ adalah penelitian yang bertujuan untuk mengetahui pengaruh antara dua variabel atau lebih. Penelitian ini menguji pengaruh product quality, brand equity, dan iklan terhadap keputusan pembelian konsumen pada produk obat nyamuk merek VAPE.

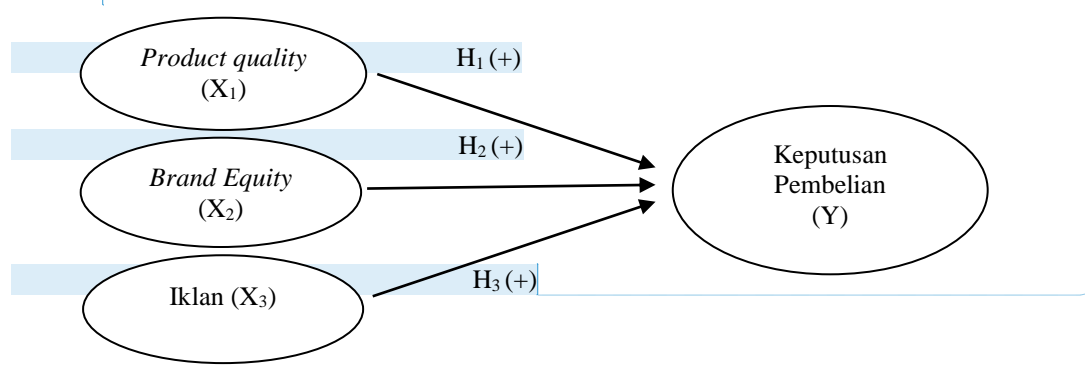

Commented [M3]: Format gambar lihat pedoman

\section{Gambar 1. Model Konseptual Penelitian}


Rasyid Ahmad Yoher, Pengaruh Product Quality, Brand...

Penelitian ini di lakukan di Kota Denpasar, lokasi ini dipilih karena terdapat beberapa masalah yang menarik untuk diteliti mengenai product quality, brand equity, dan iklan terhadap keputusan pembelian konsumen pada produk obat nyamuk merek VAPE. Objek penelitian ini adalah keputusan pembelian konsumen pada produk obat nyamuk merek VAPE di Kota Denpasar. Variabel yang digunakan dalam penelitian ini antara lain Variabel Terikat (Y), Variabel terikat adalah variabel yang dipengaruhi atau yang akan menjadi akibat dari variabel bebas. Variabel terikat adalah penelitian ini adalah Keputusan pembelian (Y). Variabel Bebas (X), Variabel bebas adalah variabel yang mempengaruhi atau menjadi sebab berubahnya atau timbulnya variabel terikat yang disimbolkan dengan tanda $\mathrm{X}$ dan variabel bebas dalam penelitian ini adalah product quality $\left(\mathrm{X}_{1}\right)$, brand equity $\left(\mathrm{X}_{2}\right)$, dan iklan $\left(\mathrm{X}_{3}\right)$.

Jenis dan sumber data dalam penelitian ini yaitu data kualitatif dan data kuantitatif. Data kualitatif dalam penelitian ini adalah nama dan pertanyaan dalam kuesioner. Data kuantitatif dalam penelitian ini adalah hasil daftar pertanyaan penelitian kuesioner. Data primer yang digunakan dalam penelitian ini adalah data yang diperoleh langsung dari responden seputar variabel yang dimaksud yaitu product quality, brand equity, dan iklan terhadap keputusan pembelian. Data sekunder dalam penelitian ini adalah gambaran umum perusahaan.

Populasi dalam penelitian ini adalah seluruh masyarakat Kota Denpasar yang membeli produk obat nyamuk merek VAPE. eknik pengambilan sampel dalam penelitian ini adalah teknik non probability sampling, teknik yang tidak memberi peluang atau kesempatan sama bagi setiap unsur atau anggota populasi 
untuk dipilih menjadi sampel. Teknik pemilihan sampel menggunakan teknik purposive sampling, yaitu penentuan sampel berdasarkan pertimbangan maupun syarat-syarat tertentu. Adapun pertimbangan yang di gunakan dalam pengambilan sampel adalah sebagai berikut 1) Responden yang pernah membeli dan menggunakan produk obat nyamuk merek VAPE 2) Konsumen memiliki usia minimal 15 tahun dan pendidikan minimal SMP dikarenakan pada pendidikan ini dianggap sudah dapat memahami isi dari kuesioner.

Menurut Ferdinand (2002:51) penentuan banyaknya sampel diukur sesuai dengan jumlah parameter yang diestimasi. Berdasarkan dari pedoman tersebut, indikator yang ada di kali 5 - 10 jumlah parameter yang diestimasi. Indikator yang digunakan dalam penelitian ini sebanyak 18, maka jumlah sampel yang digunakan adalah 5 - 10 jumlah parameter yang diestimasi dikali dengan jumlah indikator penelitian sebesar $18=$ rentang 90 sampai 180 sampel. Ukuran sampel yang digunakan berjumlah 120 responden, karena 120 responden sudah termasuk dalam rentang 90 sampai 180 yang diestimasi.

Metode pengumpulan data yang digunakan dalam penelitian ini adalah metode dengan kuesioner. Kuesioner yaitu metode pengumpulan data yang dilakukan dengan cara mengajukan pertanyaan yang telah dipersiapkan dalam bentuk daftar pertanyaan secara tertulis mengenai product quality, brand equity dan iklan terhadap keputusan pembelian. Metode kuesioner ini menggunakan skala likert. Skala likert digunakan untuk mengukur sikap, pendapat, serta persepsi seseorang atau kelompok tentang kejadian sosial. Menggunakan skala likert maka, variabel yang akan diukur dijabarkan menjadi sub variabel, 
Rasyid Ahmad Yoher, Pengaruh Product Quality, Brand...

dijabarkan menjadi indikator yang dapat diukur dan indikator terukur inilah yang perlu dijawab responden. Skala likert yang digunakan yaitu skor 1 untuk sangat tidak setuju (STS) sampai dengan skor 5 untuk sangat setuju (SS).

Penelitian ini menggunakan instrumen kuesioner sebagai alat pengumpul data, maka perlu dilakukan uji validitas dan reliabilitas agar kuesioner layak untuk digunakan sebagai sumber data. Uji validitas bertujuan untuk memeriksa apakah isi kuesioner sudah tepat untuk mengukur apa yang ingin diukur dan cukup dipahami oleh semua responden yang diindikasikan oleh besar kecilnya persentase jawaban responden yang tidak terlalu menyimpang dari jawaban reponden yang lainnya. Uji reliabilitas bertujuan untuk mencari tahu sampai sejauh mana konsistensi alat ukur yang digunakan, sehingga bila alat ukur tersebut digunakan kembali untuk meneliti objek yang sama dengan teknik yang sama walaupun waktunya berbeda, maka hasil yang diperoleh akan sama.

Teknik analisis data yang digunakan pada penelitian ini adalah model regresi linear berganda. Model regresi linear berganda ini bertujuan untuk mengetahui pengaruh product quality, brand equity, dan iklan terhadap keputusan pembelian. Berdasarkan hal tersebut maka metode analisis yang digunakan adalah model regresi linear berganda, yang persamaannya dapat dikemukakan sebagai berikut (Wirawan, 2002:293):

$$
Y=a+b_{1} . X_{1}+b_{2} . X_{2}+b_{3} . X_{3}+e_{i} .
$$

Keterangan:

$\mathrm{Y} \quad=$ Keputusan pembelian

$\mathrm{X}_{1} \quad=$ Pengaruh product quality

$\mathrm{X}_{2} \quad=$ Pengaruh brand equity

$\mathrm{X}_{3} \quad=$ Pengaruh iklan 


$$
\begin{array}{ll}
\mathrm{a}_{1} & =\text { Konstanta regresi } \\
\mathrm{b}_{1} & =\text { Koefisien variabel product quality } \\
\mathrm{b}_{2} & =\text { Koefisien variabel } \text { brand equity } \\
\mathrm{b}_{3} & =\text { Koefisien variabel iklan } \\
\mathrm{e}_{\mathrm{i}} & =\text { Error of term atau variabel pengganggu }
\end{array}
$$

\section{HASIL DAN PEMBAHASAN}

Responden dari penelitian ini digambarkan secara umum dengan menyajikan karakteristik yang di lihat dari beberapa variable demografi yaitu jenis

\begin{tabular}{|c|c|c|c|c|}
\hline \multirow{2}{*}{ No. } & \multirow{2}{*}{$\begin{array}{c}\text { Variabel } \\
\text { karakteristik }\end{array}$} & \multirow{2}{*}{ Klasifikasi } & \multirow{2}{*}{$\begin{array}{l}\text { Jumlah } \\
\text { (orang) }\end{array}$} & \multirow{2}{*}{$\begin{array}{c}\text { Persentase } \\
\%\end{array}$} \\
\hline & & & & \\
\hline \multirow{3}{*}{1} & \multirow{3}{*}{ Jenis Kelamin } & Laki-laki & 52 & 43,4 \\
\hline & & Perempuan & 68 & 56,6 \\
\hline & & Total & 120 & 100 \\
\hline \multirow{5}{*}{2} & \multirow{5}{*}{ Usia } & $15-25$ & 25 & 20,8 \\
\hline & & $25-35$ & 39 & 32,5 \\
\hline & & $35-45$ & 30 & 25 \\
\hline & & di atas 45 & 26 & 21,7 \\
\hline & & Total & 120 & 100 \\
\hline \multirow{5}{*}{3} & \multirow{5}{*}{ Pekerjaan } & Pelajar/Mahasiswa & 23 & 19,2 \\
\hline & & Pegawai Negeri & 32 & 26,7 \\
\hline & & Pegawai Swasta & 31 & 25,8 \\
\hline & & Wiraswasta & 34 & 28,3 \\
\hline & & Total & 120 & 100 \\
\hline \multirow{5}{*}{4} & \multirow{5}{*}{ Penghasilan perbulan (Rp) } & Belum berpenghasilan & 19 & 15,8 \\
\hline & & di bawah Rp. 2 juta & 37 & 30,9 \\
\hline & & Rp. 2 juta - Rp. 4 juta & 39 & 32,5 \\
\hline & & di atas Rp. 4 juta & 25 & 20,8 \\
\hline & & Total & 120 & 100 \\
\hline
\end{tabular}
kelamin, usia, pekerjaan dan penghasil perbulan. Jumlah responden yang digunakan dalam penelitian ini sebanyak 120 orang responden.

Tabel 1.

Karakteristik Responden

Sumber : Data Diolah, 2017

Berdasarkan Tabel 1 responden dikelompokkan berdasarkan jenis kelamin, usia pekerjaan, dan penghasilan perbulan. Hasil menunjukkan bahwa mayoritas 
Rasyid Ahmad Yoher, Pengaruh Product Quality, Brand...

responden adalah perempuan dengan presentase sebesar 56,6 persen dan responden laki-laki dengan presentase sebesar 43,4 persen. Pengelompokan berikut berdasarkan usia menunjukkan mayoritas responden adalah yang berusia 25-35 tahun dengan persentase sebesar 32,5. Berdasarkan perhitungan ini didapatkan fakta bahwa mayoritas pembeli sekaligus pengguna produk obat nyamuk merek VAPE adalah kaum dewasa diusia yang telah di tentukan.

Deskripsi responden berdasarkan jenis pekerjaannya atau statusnya saat ini, adalah responden yang masih berstatus wiraswasta memiliki persentase terbesar yaitu 28,3 persen, responden yang bekerja sebagai pelajar/mahasiswa dengan persentase sebesar 19,2 setelah itu diikuti oleh pegawai negeri dengan persentase sebesar 26,7 dan yang terakhir diikuiti oleh pegawai negeri swasta dengan persentase sebesar 25,8. Pengelompokan responden berdasarkan tingkat pendapatan per bulan menunjukkan bahwa mayoritas responden memiliki tingkat pendapatan Rp. 2 juta - Rp. 4 juta dengan persentase sebesar 32,5. Kemudian diikuti oleh yang belum berpenghasilan dengan persentase sebesar 15,8 persen setelah itu yang berpenghasilan dibawah Rp. 2 juta dengan persentase sebesar 30,9 persen lalu yang terakhir dengan pendapatan diatas Rp. 4 juta dengan persentase sebesar 15,8 persen.

Suatu instrumen dikatakan valid jika korelasi antara skor faktor dengan skor total bernilai positif dan nilainya lebih dari $0,30(r>0,3)$ terhadap 30 sampel penelitian. Tabel 2 menyajikan hasil uji validitas instrumen penelitian. 
Tabel 2.

Hasil Uji Validasi

\begin{tabular}{cccc}
\hline Variabel & Indikator & Koefisien Korelasi & Keterangan \\
\hline & $\mathrm{X}_{1.1}$ & 0,671 & Valid \\
& $\mathrm{X}_{1.2}$ & 0,547 & Valid \\
Product Quality & $\mathrm{X}_{1.3}$ & 0,569 & Valid \\
$\left(\mathrm{X}_{1}\right)$ & $\mathrm{X}_{1.4}$ & 0,556 & Valid \\
& $\mathrm{X}_{1.5}$ & 0,525 & Valid \\
& $\mathrm{X}_{1.6}$ & 0,671 & Valid \\
& $\mathrm{X}_{1.7}$ & 0,505 & Valid \\
& $\mathrm{X}_{2.1}$ & 0,748 & Valid \\
Brand Equity & $\mathrm{X}_{2.2}$ & 0,854 & Valid \\
$\left(\mathrm{X}_{2}\right)$ & $\mathrm{X}_{2.3}$ & 0,805 & Valid \\
& $\mathrm{X}_{2.4}$ & 0,794 & Valid \\
& $\mathrm{X}_{3.1}$ & 0,805 & Valid \\
Iklan $\left(\mathrm{X}_{3}\right)$ & $\mathrm{X}_{3.2}$ & 0,745 & Valid \\
& $\mathrm{X}_{3.3}$ & 0,855 & Valid \\
Keputusan & $\mathrm{Y}_{1}$ & 0,437 & Valid \\
Pembelian & $\mathrm{Y}_{2}$ & 0,804 & Valid \\
& $\mathrm{Y}_{3}$ & 0,765 & Valid \\
(Y) & $\mathrm{Y}_{4}$ & 0,72 & Valid \\
\hline
\end{tabular}

Sumber: Data Diolah, 2017

Hasil uji validitas pada Tabel 2 di atas menunjukkan bahwa seluruh variabel memiliki nilai koefisien korelasi dengan skor total seluruh item pernyataan lebih besar dari 0,30 . Hal ini menunjukkan bahwa butir-butir pernyataan dalam instrument penelitian tersebut valid.

Suatu instrument dikatakan reliabel, jika instrument tersebut memiliki nilai Alpha Cronbach lebih dari 0,60 terhadap 30 sampel penelitian. Adapun hasil dari uji reliabilitas dapat ditunjukkan pada tabel berikut. 
Tabel 3.

Hasil Uji Reliabilitas

\begin{tabular}{rlrl}
\multicolumn{4}{c}{ Hasil Uji Reliabilitas } \\
\hline No. & Variabel & Cronbach's Alpha & Keterangan \\
\hline $\mathbf{1}$ & Product Quality $\left(\mathrm{X}_{1}\right)$ & 0,732 & Reliabel \\
$\mathbf{2}$ & Brand Equity $\left(\mathrm{X}_{2}\right)$ & 0,815 & Reliabel \\
$\mathbf{3}$ & Iklan $\left(\mathrm{X}_{3}\right)$ & 0,822 & Reliabel \\
$\mathbf{4}$ & Keputusan Pembelian $(\mathrm{Y})$ & 0,77 & Reliabel \\
\hline lata & &
\end{tabular}

Hasil uji reliabilitas yang disajikan dalam Tabel 3 menunjukkan bahwa seluruh instrumen penelitian memiliki koefisien Cronbach's Alpha lebih dari 0,60. Hal ini dapat dikatakan bahwa semua instrumen reliabel sehingga dapat digunakan untuk melakukan penelitian.

Uji ini bertujuan untuk mengetahui apakah residual dari model regresi yang dibuat berdistribusi normal atau tidak. Untuk menguji apakah data yang digunakan normal atau tidak dapat dilakukan dengan menggunakan uji Kolmogorov Sminarnov. Apabila koefisien Asymp. Sig. (2-tailed) lebih besar dari 0,05 maka data tersebut dikatakan berdistribusi normal.

Tabel 4.

Hasil Uji Normalitas

\begin{tabular}{ccr}
\hline & & Unstandardized Residual \\
$\mathrm{N}$ & & 120 \\
& & 0,412 \\
& Kolmogorov-Smirnov Z & 0,996 \\
\hline
\end{tabular}

Berdasarkan Tabel 4 dapat diketahui bahwa nilai Kolmogorov Sminarnov (K-S) sebesar 0,412, sedangkan nilai Asymp. Sig. (2-tailed) sebesar 0,996. Hasil tersebut mengindikasikan bahwa model persamaan regresi tersebut berdistribusi normal karena nilai Asymp. Sig. (2-tailed) 0,996 lebih besar dari nilai alpha 0,05.

Uji ini bertujuan untuk menguji apakah pada model regresi ditemukan adanya korelasi antar variabel bebas. Adanya multikolinearitas dapat dilihat dari 
nilai tolerance atau variance inflation factor (VIF). Jika nilai tolerance lebih dari $10 \%$ atau VIF Kurang dari 10, maka dikatakan tidak ada multikolinearitas.

Tabel 5.

Hasil Uji Multikolinearitas

\begin{tabular}{lll}
\hline Variabel & Tolerance & \multicolumn{2}{c}{ VIF } \\
\hline Product Quality $\left(\mathrm{X}_{1}\right)$ & 0,643 & 1,555 \\
Brand Equity $\left(\mathrm{X}_{2}\right)$ & 0,544 & 1,838 \\
Iklan $\left(\mathrm{X}_{3}\right)$ & 0,695 & 1,438 \\
\hline Data Diolah, 2017 & &
\end{tabular}

Sumber: Data Diolah, 2017

Berdasarkan Tabel 5 dapat diketahui bahwa nilai tolerance dan VIF dari seluruh variable menunjukkan bahwa nilai tolerance untuk setiap variabel lebih besar dari $10 \%$ dan nilai VIF lebih kecil dari 10 yang berarti model persamaan regresi bebas dari multikolinearitas.

Uji ini bertujuan untuk mengetahui apakah dalam model regresi terjadi ketidaksamaan varians dari residual satu pengamatan ke pengamatan lain yang dilakukan dengan uji glejser. Jika tidak ada satu pun variabel bebas yang berpengaruh signifikan terhadap nilai absolute residual atau nilai signifikansinya di atas 0,05 maka tidak mengandung gejala heteroskedastisitas.

Tabel 6.

Hasil Uji Heteroskedastisitas

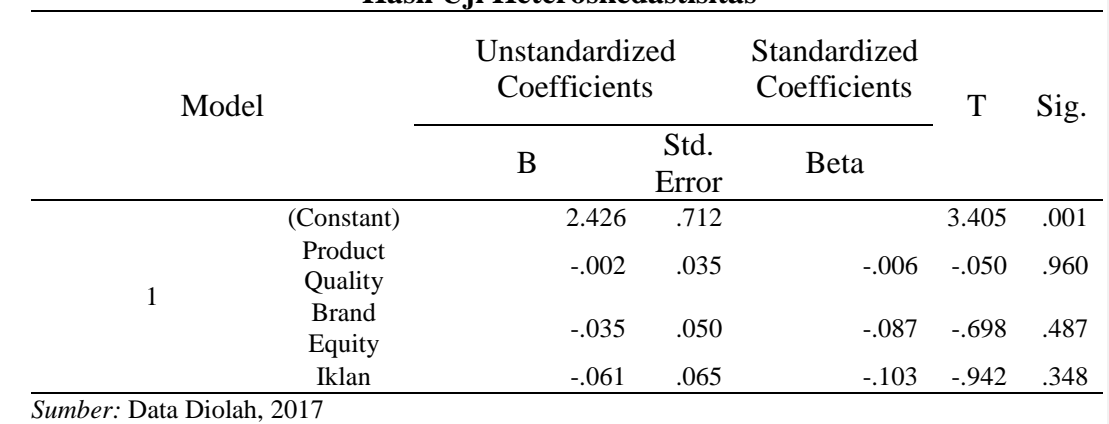


Rasyid Ahmad Yoher, Pengaruh Product Quality, Brand...

Pada Tabel 6 dapat diketahui bahwa nilai Sig. dari variabel product quality, brand equity dan iklan, masing-masing sebesar 0,960; 0,487 dan 0,348 Nilai tersebut lebih besar dari 0,05 yang berarti tidak terdapat pengaruh antara variabel bebas terhadap absolute residual. Dengan demikian, model yang dibuat tidak mengandung gejala heteroskedastisitas.

Kriteria pengujian untuk menjelaskan interpretasi pengaruh antar masingmasing variabel. Apabila nilai signifikansi $<0.05$ maka $\mathrm{H}_{0}$ ditolak dan $\mathrm{H}_{1}$ diterima. Sebaliknya, jika nilai signifikansi > 0.05 maka $\mathrm{H}_{0}$ diterima dan $\mathrm{H}_{1}$ ditolak. Berdasarkan hasil analisis pengaruh product quality terhadap keputusan pembelian diperoleh nilai signifikansi sebesar 0,008 dengan nilai koefisien regresi 0,245. Nilai Signifikansi $0,008<0,05$ mengindikasikan bahwa $\mathrm{H}_{0}$ ditolak dan $\mathrm{H}_{1}$ diterima. Hasil ini mempunyai arti bahwa product quality berpengaruh positif dan signifikan terhadap keputusan pembelian.

Berdasarkan hasil analisis pengaruh brand equity terhadap keputusan pembelian diperoleh nilai signifikansi sebesar 0,003 dengan nilai koefisien regresi 0,297. Nilai Signifikansi $0,003<0,05$ mengindikasikan bahwa $\mathrm{H}_{0}$ ditolak dan $\mathrm{H}_{1}$ diterima. Hasil ini mempunyai arti bahwa brand equity berpengaruh positif dan signifikan terhadap keputusan pembelian.

Berdasarkan hasil analisis pengaruh iklan terhadap keputusan pembelian diperoleh nilai signifikansi sebesar 0,019 dengan nilai koefisien regresi 0,208. Nilai Signifikansi $0,019<0,05$ mengindikasikan bahwa $\mathrm{H}_{0}$ ditolak dan $\mathrm{H}_{1}$ diterima. Hasil ini mempunyai arti bahwa iklan berpengaruh positif dan signifikan terhadap keputusan pembelian. 
Signifikansi Tabel ANOVA menunjukkan besarnya angka probabilitas atau signifikansi pada perhitungan ANOVA. Nilai yang tertera digunakan untuk uji kelayanan Model Analisis (dimana sejumlah variabel x mempengaruhi variabel y) dengan ketentuan angka probabilitas yang baik untuk digunakan sebagai model regresi harus $<0,05$. Nilai ini bisa dilihat pada kolom Signifikansi. Jika signifikansi < 0,05, maka Model Analisis dianggap layak. Jika nilai signifikansi > 0,05, maka Model Analisis dianggap tidak layak.

Tabel 7.

\section{Uji Anova}

\begin{tabular}{|c|c|c|c|c|c|c|}
\hline \multicolumn{2}{|c|}{ Model } & $\begin{array}{c}\text { Sum of } \\
\text { Squares }\end{array}$ & Df & $\begin{array}{l}\text { Mean } \\
\text { Square }\end{array}$ & $\mathrm{F}$ & Sig. \\
\hline \multirow{3}{*}{1} & Regression & 215.920 & 3 & 71.973 & 24.270 & $.000^{\mathrm{a}}$ \\
\hline & Residual & 344.001 & 116 & 2.966 & & \\
\hline & Total & 559.921 & 119 & & & \\
\hline
\end{tabular}

Sumber: Data Diolah, 2017

Tabel 7 hasil uji anova (UJI F) di atas, diperoleh nilai antar kelompok pembanding $=3$, nilai dalam kelompok penyebut $=119$, pada alfa $=0,05$ maka nilai $\mathrm{F}$ tabelnya adalah $\mathrm{F} 0,05(3,119)=2,68$. Sedang $\mathrm{F}$ hitung $=24,270$. Nilai Fhitung $>\mathrm{F}$ tabel, 24,270 > 2,68, dengan nilai signifikansi $0,000<0,05$. Maka H0 ditolak pada taraf nyata 0,05 (H1 diterima). Kesimpulannya, pada kelompok yang diuji memiliki perbedaan yang nyata (signifikan) berarti bahwa product quality, brand equity dan iklan secara simultan berpengaruh signifikan terhadap keputusan pembelian.

Nilai determinasi total sebesar 0,386 mempunyai arti bahwa sebesar 38,6\% variasi keputusan pembelian dipengaruhi oleh variasi product quality, brand equity, dan iklan sedangkan sisanya sebesar $61,4 \%$ dijelaskan oleh faktor lain yang tidak dimasukkan ke dalam model. 
Rasyid Ahmad Yoher, Pengaruh Product Quality, Brand...

Berdasarkan hasil pengujian hipotesis, pengaruh product quality terhadap keputusan pembelian dengan hasil signifikansi $0,008<0,05$ serta koefisien beta sebesar 0,245 menunjukan bahwa product quality berpengaruh secara positif dan signifikan terhadap keputusan pembelian. Hal ini menunjukkan bahwa semakin baik product quality yang di milik suatu produk, maka akan meningkatkan keputusan pembelian konsumen pada produk obat nyamuk merek VAPE.

Ackaradejruangsri (2013) menyatakan bahwa keputusan pembelian konsumen dipengaruhi oleh product quality dimana mempunyai pengaruh positif dan signifikan terhadap keputusan pembelian. Chi et al. (2008) Menyatakan bahwa jika produk memiliki kualitas yang lebih baik, pelanggan akan lebih cenderung untuk membelinya. Jalilvand et al. (2011) meneliti kualitas produk pada keputusan pembelian, menemukan bahwa product quality memiliki pengaruh positif dan signifikan terhadap keputusan pembelian. Gogoi et al. (2013); Tariq dkk, (2013); Tih \& Lee (2013); Dursun et al. (2011); Bao et al. (2011); Guterman (2012); Dick et al. (1995) menemukan bahwa product quality berpengaruh positif dan signifikan terhadap keputusan pembelian konsumen.

Berdasarkan hasil pengujian hipotesis, pengaruh brand equity terhadap keputusan pembelian dengan hasil signifikansi $0,003<0,05$ serta koefisien beta sebesar 0,297 menunjukan bahwa brand equity berpengaruh secara positif dan signifikan terhadap keputusan pembelian. Hal ini menunjukkan bahwa semakin baik brand equity dibenak konsumen, maka akan meningkatkan keputusan pembelian konsumen pada produk obat nyamuk merek VAPE. 
Monavvarian, (2015) menyatakan bahwa brand equity memiliki pengaruh positif dan signifikan terhadap keputusan pembelian konsumen. Menurut Lekprayura (2012) menyatakan bahwa brand equity berpengaruh positif dan signifikan terhadap keputusan pembelian konsumen. Gunawardane (2015) juga mengemukakan bahwa brand equity berpengaruh positif dan signifikan terhadap keputusan pembelian konsumen. Heidarian (2015) menyatakan dalam penelitian bahwa brand equity berpengaruh positif dan signifikan terhadap keputusan pembelian konsumen.

Berdasarkan hasil pengujian hipotesis, pengaruh iklan terhadap keputusan pembelian dengan hasil signifikansi $0,019<0,05$ serta koefisien beta sebesar 0,208 menunjukan bahwa iklan berpengaruh secara positif dan signifikan terhadap keputusan pembelian. Hal ini menunjukkan bahwa semakin sering iklan muncul, maka akan meningkatkan keputusan pembelian konsumen pada produk obat nyamuk merek VAPE.

Penelitian yang dilakukan oleh Remalya (2013) periklanan memiliki pengaruh positif dan signifikan terhadap keputusan pembelian konsumen. Penelitian yang dilakukan oleh Handayani dkk. (2012) mengenai pengaruh dari iklan terhadap keputusan pembelian juga mendapatkan hasil yang sama dimana iklan mempunyai pengaruh positif dan signifikan terhadap keputusan pembelian konsumen. Serta menurut penelitian yang dilakukan oleh Putri dan Putong (2012) periklanan berpengaruh positif dan signifikan terhadap keputusan pembelian konsumen. Hal tersebut menunjukkan bahwa iklan mampu meningkatkan sikap konsumen dalam keputusan pembelian. 
Rasyid Ahmad Yoher, Pengaruh Product Quality, Brand...

\section{SIMPULAN DAN SARAN}

Berdasarkan hasil pembahasan, maka dapat ditarik beberapa simpulan diantaranya bahwa Variabel product quality berpengaruh positif dan signifikan terhadap keputusan pembelian konsumen pada produk obat nyamuk merek VAPE. Artinya bahwa semakin tinggi kualitas produk maka akan semakin meningkat keputusan pembelian konsumen terhadap produk obat nyamuk merek VAPE. Variabel brand equity berpengaruh positif dan signifikan terhadap keputusan pembelian konsumen pada produk obat nyamuk merek VAPE. Artinya bahwa semakin baik brand equity maka akan semakin tinggi pula keputusan pembelian konsumen terhadap keputusan pembelian konsumen terhadap produk obat nyamuk merek VAPE. Variabel iklan berpengaruh terhadap positif dan signifikan keputusan pembelian konsumen pada produk obat nyamuk merek VAPE. Artinya bahwa semakin sering iklan pada produk obat nyamuk VAPE muncul maka semakin tinggi pula keputusan pembelian konsumen pada produk obat nyamuk merek VAPE.

Berdasarkan hasil penelitian serta simpulan diatas, maka berikut beberapa saran yang dapat diberikan yaitu produk obat nyamuk merek VAPE harus selalu memperhatikan kualitas produk serta juga mampu meningkatkan ekuitas merek secara keseluruhan dan mampu pula menciptakan kreasi dalam mengiklankan produk obat nyamuk yang ditawarkan kepada konsumen sehingga keputusan konsumen untuk melakukan pembelian semakin meningkat. VAPE perlu juga memperhatikan produk-produk yang dipasarkan baik dari segi kemasan produk, bentuk dan label produk, karena hal ini akan berpengaruh terhadap penilaian 
konsumen terhadap produk obat nyamuk merek VAPE yang akan dibeli. Bagi peneliti berikutnya, agar menggunakan jumlah sampel yang lebih besar, ruang lingkup penelitian yang lebih luas, serta perusahaan lebih spesifik menghubungkan variabel-variabel lain yang dapat mempengaruhi keputusan pembelian. Selain itu agar hasil penelitian selanjutnya dapat lebih digeneralisasi.

\section{REFERENSI}

Aaker., and Keller, 2010. Consumer Evaluation of Brand Extension. Journal of Marketing. 5(4): 27-41.

Abbas Monavvarian, N. A, 2015. Studying The Effects Of Brand Equity On The Consumers Responses In The Service Markets. International Journal of Economics, Commerce and Management, 3(3): 60-78.

Ackaradejruangsri, P. 2013. The Effect of Product Quality Attributes on Thai Consumer's Buying Decision. Ritsumeikan Journal of Asia Pasific Studies, 33: 14-24.

Al Ries. Laura Ries, 2000. The 22 Immutable Laws of Branding. Gramedia Pustaka Utama.

Andrie Ch., Salhuteru., dan Harold Hursepuny, 2013. Analisa Ekuitas Merek terhadap keputusan Pembelian Sepeda Motor Merek Yamaha di PT Hasjrat Abadi Cabang Ambon. Jurnal Manajemen Ekonomi dan akuntansi. 2 (1): 1-122.

Assauri, Sofjan. 2004. Manajemen Pemasaran. Jakarta: Rajawali Press.

Ayu Putri Anggrihita Prabhawedasattya, I Gusti., dan Kerti Yasa, Ni. Nyoman, 2014. Pengaruh Ekuitas Merek terhadap Preferensi Merek dan Niat Beli Konsumen pada Produk Iphone di Kota Denpasar. Jurnal Manajemen Ekonomi. 16(1): 1525-1551.

Bao, Y., Bao, Y., and Sheng, S. 2011. Motivating Purchase of Private Brands: Effects of Store Image, Product Signatories, and Quality Variation. Journal of Business Research, 64: 220-226. 
Rasyid Ahmad Yoher, Pengaruh Product Quality, Brand...

Basu Swastha Dharmmesta., dan T. Hani Handoko. 2000. Manajemen Pemasaran, Analisa Perilaku Konsumen. Yogyakarta: BPFEYogyakarta.

Blackwell, Roger D., Paul W. Miniard., and James F. Engel 2005. Consumer Behavior (10 th), Thomson Learning.

Brunso K., Bredahl L., Grunert KG., and Scholderer J. 2005. Consumer perception of the quality of beef resulting from various fattening regimes. Livestock Prod. Sci., 94(1/2): 83-93.

D. R. Rawung., S. G. Oroh., dan J. S. B. Sumarauw 2015. Analisis kualitas produk, merek dan harga terhadap keputusan pembelian sepeda motor Suzuki pada PT. Sinar Galesong Pratama Manado. Jurnal EMBA. 3(3): 1298-1308.

Eko Nurdin Kurnianto., dan Budi Astuti, 2013. Analisis pengaruh komponen pembentuk akuitas merek terhadap minat beli. Jurnal Manajemen Ekonomi Nasional. 4 (1): 458-466

Elham Heidarian, A. K. 2015. The effect of brand equity on consumer purchasing behavior Case study: Food famous brands in Mashhad Industrial Town. Applied mathematics in Engineering, Ma nagement and Technology, 4(6): 335-340.

Fadli dan Qomariah, Inneke, 2008, Analisis Pengaruh Faktor-Faktor Ekuitas Merek Sepeda Motor Merek Honda Terhadap Keputusan Pembelian di Sumatera, Jurnal Manajemen Bisnis, 1(2): 47-60.

Gaspersz, Vincent. 2005. Sistem Manajemen Kinerja Terintegrasi Balanced Scorecard Dengan Six Sigma Untuk Organisasi Bisnis dan Pemeritah. Jakarta: Gramedia Pustaka Utama.

Ghozali, Imam, 2013. Aplikasi Analisis Multivariate dengan Program SPSS. Yogyakarta: Badan Penerbit BPFE.

Gunawardane, N. R. 2015. Impact of Brand Equity towards Purchasing Desition: A Situation on Mobile Telecommunication Services of Sri Lanka. Journal of Marketing Management, 3: 100-117.

Johan Wahyudi Amzah, 2010. Pengaruh gengsi, kepuasan dan komunikasi perusahaan terhadap Woth of Mouth dan niat beli kembali dengan variabel antara identifikasi merk (kasus pada produk Blackberry di Surabaya. Jurnal Ekonomi Erlangga. 1(3): 1-128 
Kambiz Heidarzadeh hanzaee., and Mohammad Javad Taghipourian, 2012. The effect of brand Credibility and Prestige on Consumers Purchase Intention in low and high product Involvement. Journal Basic. Appl. Sci. Res., 2(2): 1281-1291

Kevin Goenawan, 2014. Pengaruh produk attributes, brand name, product price, dan social influence terhadap purchase intention android smartphone di Surabaya. Jurnal Ilmiah Ekonomi. 3(1): 1-17

Kotler dan Keller. 2009. Manajemen Pemasaran. Jilid I. Edisi ke 13. Jakarta: Erlangga.

Kosasih, 2013. Pengaruh perilaku konsumen terhadap keputusan pembelian sepeda motor Yamaha di dealer Arista Johar. Jurnal Manajemen. 10(13): 321-330.

Kuenzel, S., dan Halliday, S. V., 2008., Investigating Antecedents and Consequences of Brand Identification. Journal of Product \& Brand Management, 17(5): 293-304.

Kusumastuti, Y.I. 2011. Komunikasi Bisnis. IPB Press. Bogor.

Lekprayura, S. 2012. Brand Equity and Factors Affecting Consumer's Purchase Intention towards Luxury Brands in Bangkok Metropolitan Area. International Journal of Social, Behavioral, Educational, Economic, Business and Industrial Engineering, 6: 2620 -2625.

Lee JW , Tai SW 2009. Determinants of product quality perceptions and their application to marketing standardization. The case of the automobile in Kazakhstan. Int. J. Emerg. Mark., 4(2): 119-136.

Levy, S., and Gendel - Guterman, H. 2012. Does advertising matter to store brand purchase intention? A conceptual framework. Journal of Product \& Brand Management, 21(2): 89 -97.

Mandey, Jilly Bernadette. 2013. Promosi, Distribusi, Harga Pengaruhnya Terhadap Keputusan Pembelian Rokok Surya Promild. Jurnal EMBA. 16(7): $2303-1174$.

Nata Wirawan., dan I Gusti Putu. 2002. Cara Mudah Memahami Statistik 2 (Statistik Inferensia) untuk ekonomi dan bisnis, Denpasar : edisi kedua, Keraras Emas.

Orth, U., Wolf, M., and Dodd, T. H. 2005. Dimensions of Wine Region Equity and Theirs Impact on Cunsumers preference. Journal of Product and Brand Management. 14(2): 88-97. 
Rasyid Ahmad Yoher, Pengaruh Product Quality, Brand...

Paul, Peter. J., dan Jerry C. Olson, 2000, Consumer Behaviour : Perilaku Konsumen dan Strategi Pemasaran, jilid 1 dan jilid 2, Jakarta : Erlangga.

Rahmadhano Ravie. 2014. Pengaruh Brand Equity Terhadap Keputusan Pembelian Konsumen Pada Peter Says Denim Di Kota Bandung. $e$ Proceeding of Management, 11(3): 610-630.

Rijswijk, Wendy Van. 2000. Consumer Perceptions of Food Quality and Safety and Their Relation to Traceability. Jurnal of Marketing. Vol. 1 Edisi 3

Rofiq, Ainur., Nanang S., dan Nita NF. 2009. Peranan Ekuitas Merek terhadap Loyalitas Pelanggan pada Industri Telepon Seluler. Paper pada National Conference on Management Research. 6(7): 56-68.

Shaharudin MR., Hassan AA., Mansor SW., Elias SJ., Harun EH., and Aziz NA 2010. The relationship between extrinsic attributes of product quality with brand loyalty on Malaysia national brand motorcycle/scooter. Canadian Soc. Sci., 6(3): 170-182.

Schiffman., dan Kanuk. 2008. Perilaku konsumen. Edisi 7. Jakarta: Indeks

Shimp, Terence A. 2003. Periklanan Promosi: Aspek Tambahan Komunikasi Pemasaran Terpadu. 5. Jakarta: Erlangga.

Tariq, M., Nawaz, M., Butt, H. and Nawaz, M. 2013, Customer Perceptions about Branding and Purchase Intention:A Study of FMCG in an Emerging Market, Journal of Basic and Applied Scientific Research, 3(2): 340 347.

Steven Edbert, Altje Tumbel, Willem Alfa Tumbuan. 2014. Pengaruh Image, Harga, Iklan dan Kualitas Produk Terhadap Keputusan Pembelian Konsumen Pada Pasta Gigi Pepsodent di Kota Manado. Jurnal EMBA, 2(3): 1035-1044. 